\title{
Removal of Indigo Carmine Dye from Aqueous Solution Using Magnesium Hydroxide as an Adsorbent
}

\author{
Thimmasandra Narayan Ramesh and Vani Pavagada Sreenivasa \\ Department of Studies and Research in Chemistry and Prof. C. N. R. Rao Centre for Advanced Materials, \\ Tumkur University, Tumkur 572 103, India \\ Correspondence should be addressed to Thimmasandra Narayan Ramesh; adityaramesh77@yahoo.com
}

Received 30 June 2015; Revised 2 October 2015; Accepted 4 October 2015

Academic Editor: Stefano Bellucci

Copyright (C) 2015 T. N. Ramesh and V. Pavagada Sreenivasa. This is an open access article distributed under the Creative Commons Attribution License, which permits unrestricted use, distribution, and reproduction in any medium, provided the original work is properly cited.

\begin{abstract}
Magnesium hydroxide is used as an adsorbent for the removal of indigo carmine dye from aqueous solution. We have investigated the effectiveness of removal of indigo carmine dye from aqueous solutions at $\mathrm{pH}$ 6-7 and 12-13 using magnesium hydroxide thereby varying the dose of the adsorbent, concentration of the dye, duration, and temperature. Structural transformations of adsorbent during the adsorption process at different $\mathrm{pH}$ values are monitored using powder X-ray diffraction and infrared spectroscopy. Different types of adsorption isotherm models were evaluated and it was found that Langmuir isotherm fits well at both $\mathrm{pH}$ values (6-7 and 12-13). Adsorption of indigo carmine onto magnesium hydroxide at $\mathrm{pH}$ 6-7/pH 12-13 follows pseudo-second order rate kinetics.
\end{abstract}

\section{Introduction}

Synthetic dyes are most widely used in textile and leather tanning industries [1]. These dyes are highly coloured, toxic, and carcinogenic in nature $[2,3]$. These effluents released from the textile and leather tanning industries containing $1 \mathrm{mg} / \mathrm{L}$ of dye are enough to impart colour to the water thus making it unpotable for daily use $[4,5]$. Dyes can be classified based on their structure, that is, azo dyes, phthalocyanine, anthraquinone dyes, and so forth [1]. Dyes are also categorized as reactive dyes, disperse dyes, direct dyes, VAT dyes, cationic dyes, acid dye, and soluble dyes. The technology used to treat dyes is based on physical, chemical, and biological methods. Precipitation, coagulation, filtration, floatation, electrochemical degradation, and advanced oxidation techniques are considered as chemical methods $[6,7]$. Adsorption, reverse osmosis, and ultrafiltration are treated as physical methods $[8,9]$. Physical methods of treatment of dyes are nondestructive as the dye transfer from water into the adsorbent occurs which generates large amount of residue. Photochemical irradiation of toxic dyes in presence of a photocatalyst is one of the alternative methods developed recently. Most common photocatalysts are titanium dioxide and zinc oxide which are semiconductors that are expensive and inefficient [10]. Biochemical methods utilize microbes whereas biotechnological methods use agrowaste and other low cost naturally occurring biomaterials for the adsorption of dyes [11-13]. Disposal of the sludge after dye adsorption/removal is of major concern. One of the cheapest and simple methods for the removal of dyes is by the process of adsorption. Most common adsorbents are activated charcoal, zeolites, layered materials, metal oxides, and graphite based compounds [9, 12-15]. Exfoliated graphite/graphite oxide possesses larger interlayer spacing and higher surface area for better adsorption capacity. Due to flexibility and ease of preparation, graphite oxide and graphiteoxide/composites $\left(\mathrm{Fe}_{3} \mathrm{O}_{4} / \mathrm{GO}\right.$; chitosan/GO; GO modified polyurethane-chitosan) are used for the removal of toxic dyes such as methylene blue, malachite green dyes, and metal ions [16-21].

These effluents cannot be treated effectively using the above compounds as each one of them has their own limitations $[22,23]$. Prior to the selection of adsorbent, it should (i) have high affinity for the dyes, (ii) be ecofriendly and safe to handle, and (iii) be universal if possible and preferably regenerative. There are no adsorbents which can 
fulfill all the requirements and proved to be effective in removing water soluble textile dyes. Indigo carmine is a synthetic dye which has been used as an antibacterial agent, biological stain, dermatological agent, and additive to poultry feed. Also it is a potent carcinogen, recalcitrant, and toxic to mammalian cells [24]. There are few reports on the use of different types of adsorbents to remove indigo carmine dye [25-27]. In our previous studies, we have explored the use of magnesium oxide, calcium oxide, calcium hydroxide as low cost adsorbents for the removal of indigo carmine, amido black 10B dye, solochrome black-T, alizarin red, indigo carmine, and so forth [28-32]. However, there are very few reports on the use of magnesium hydroxide as an adsorbent. In this paper, we have explored the use of magnesium hydroxide as a low cost adsorbent for the removal of indigo carmine dye in aqueous solution by estimating the adsorption capacity at different experimental conditions and evaluated various types of adsorption isotherms.

\section{Experimental Section}

2.1. Chemicals Used. The chemicals used are of analytical grade. Magnesium oxide Lite (Merck, India), indigo carmine dye, concentrated hydrochloric acid, and sodium hydroxide were purchased from SD-Fine Chemicals, India, and used without purification.

2.2. Preparation of Magnesium Hydroxide. About $5 \mathrm{~g}$ of magnesium oxide was added to $100 \mathrm{~mL}$ of distilled water and stirred for 4 days at room temperature. The solid was filtered and dried at $65^{\circ} \mathrm{C}$ for 24 hours.

2.3. Indigo Carmine Dye Solution. Indigo carmine dye solution (stock) was prepared by dissolving $50 \mathrm{mg}$ of indigo carmine dye in $1000 \mathrm{~mL}$ of distilled water $\left(1.0721 \times 10^{-4} \mathrm{M}\right)$. About $50 \mathrm{~mL}$ of $1.0721 \times 10^{-4} \mathrm{M}$ indigo carmine dye solution was taken and diluted with $100 \mathrm{~mL}$ of distilled water $\left(0.53605 \times 10^{-4} \mathrm{M}\right)$. Series of dye concentrations in the range of $1.0721 \times 10^{-6} \mathrm{M}$ to $5.3605 \times 10^{-5} \mathrm{M}$ or $0.05 \mathrm{mg}$ to $0.25 \mathrm{mg}$ of indigo carmine $/ 10 \mathrm{~mL}$ were prepared by transferring $2 \mathrm{~mL}$, $4 \mathrm{~mL}, 6 \mathrm{~mL}, 8 \mathrm{~mL}$, and $10 \mathrm{~mL}$ of the dye solution followed by dilution using $10 \mathrm{~mL}$ of distilled water. By using $1 \mathrm{M} \mathrm{HCl}$ or $1 \mathrm{M} \mathrm{NaOH}$, the $\mathrm{pH}$ of the indigo carmine dye solution was adjusted to $6-7 / 12-13$, to examine the effect of $\mathrm{pH}$ on the adsorption of dye on magnesium hydroxide.

2.4. Adsorption Measurements. Kinetic experiments were carried out using $40 \mathrm{mg}$ of adsorbent-magnesium hydroxide in $10 \mathrm{~mL}$ of indigo carmine solution of known concentration $(0.25 \mathrm{mg}$ of indigo carmine $/ 10 \mathrm{~mL})$ at room temperature (298-301 K). Indigo carmine solutions of different concentrations $\left(0.05 \mathrm{mg}\right.$ to $0.25 \mathrm{mg} / 10 \mathrm{~mL}$ or $1.0721 \times 10^{-5} \mathrm{M}$ to $5.3605 \times$ $10^{-5} \mathrm{M}$ ) were prepared and examined for the percentage of adsorption of magnesium oxide of different quantities, that is, $20 \mathrm{mg}, 40 \mathrm{mg}, 60 \mathrm{mg}$, and $80 \mathrm{mg}$.

The temperature effect on the adsorption of indigo carmine dye solutions (at different $\mathrm{pH}$ values, dosage$40 \mathrm{mg}$ ) was measured. The effect of temperature as a function

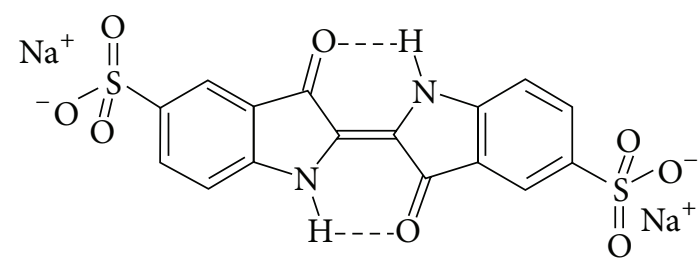

FIgURE 1: The structure of indigo carmine dye.

of time $(10,20,30,40$, and 50 minutes) on the removal of indigo carmine dye in aqueous solution was examined at $\mathrm{pH}=6-7$ and $\mathrm{pH}=12-13$ (dose of magnesium hydroxide was fixed at $40 \mathrm{mg}$ ).

2.5. Characterization. Elico CL-63 colorimeter was used for the measurement of concentration of the indigo carmine solutions. The wavelength was fixed at $600 \mathrm{~nm}\left(\lambda_{\max }\right)$ in the $\mathrm{pH}$ range of $6-13$. All the samples were characterized by powder X-ray diffraction (pXRD) using Bruker D8 advanced diffractometer ( $\mathrm{CuK} \alpha$ source $\lambda=1.5418 \AA$ ) scan rate $2^{\circ} \mathrm{min}^{-1}$ (steps: $0.02^{\circ}$-scan range of $10-65^{\circ}$ ) which was used to determine the crystal structure of magnesium hydroxide prepared and the products obtained on ageing at different $\mathrm{pH}$ values. Fourier transform infrared spectra were recorded by pellet technique using Jasco (FTIR-4100 model) FT-IR spectrometer.

\section{Results and Discussion}

The structure of indigo carmine dye $\left(\mathrm{C}_{16} \mathrm{~N}_{2} \mathrm{H}_{8} \mathrm{Na}_{2} \mathrm{O}_{8} \mathrm{~S}_{2}\right.$ molecular weight $466.36 \mathrm{~g} \mathrm{~mol}^{-1}$ ) $3,3^{\prime}$-dioxi-2,2' -bis-Indilyden-5.5 $5^{\prime}$-disulfonic acid disodium salt is shown in Figure 1.

The absorbance values of indigo carmine solution $\left(0.53605 \times 10^{-4} \mathrm{~mol} \mathrm{~L}^{-1}\right)$ was scanned at different wavelengths.

Figure 2 shows the powder X-ray diffraction pattern of magnesium hydroxide prepared by stirring magnesium oxide in water at ambient conditions, $\mathrm{pH}$ 6-7. The peak positions in the X-ray pXRD pattern of the magnesium oxide aged in water match magnesium hydroxide. The magnesium hydroxide crystallizes in hexagonal system (space group $\mathrm{P}_{-3 \mathrm{ml}}$ ) with the lattice parameters $a=3.14 \AA ; b=3.12 \AA$, and $c=4.64 \AA$; $\alpha=90^{\circ}, \beta=90^{\circ}$, and $\gamma=120^{\circ}$ (ICSD code: 00920 ).

The infrared spectrum is sensitive to functional groups and hydrogen bonds and can provide supplementary data to powder X-ray diffraction data. Infrared spectral data of the magnesium hydroxide sample aged at $\mathrm{pH}$ 6-7 (see Figure 3) shows bands in the range of $3000 \mathrm{~cm}^{-1}$ to $3700 \mathrm{~cm}^{-1}$ which arise due to $\mathrm{O}-\mathrm{H}$ stretching modes of water molecules or hydroxyl groups. We observe a pair of peaks at 3697 and $3447 \mathrm{~cm}^{-1}$ due to lattice vibration of water molecules and $\mathrm{OH}$ stretching modes of hydroxyl sheets of magnesium hydroxide [33-35].

The structure of magnesium hydroxide comprises hexagonal close packing of hydroxyl ions in which magnesium ions occupy octahedral vacant sites thus resulting in the formation of layers. These layers are stacked on top of each other. 


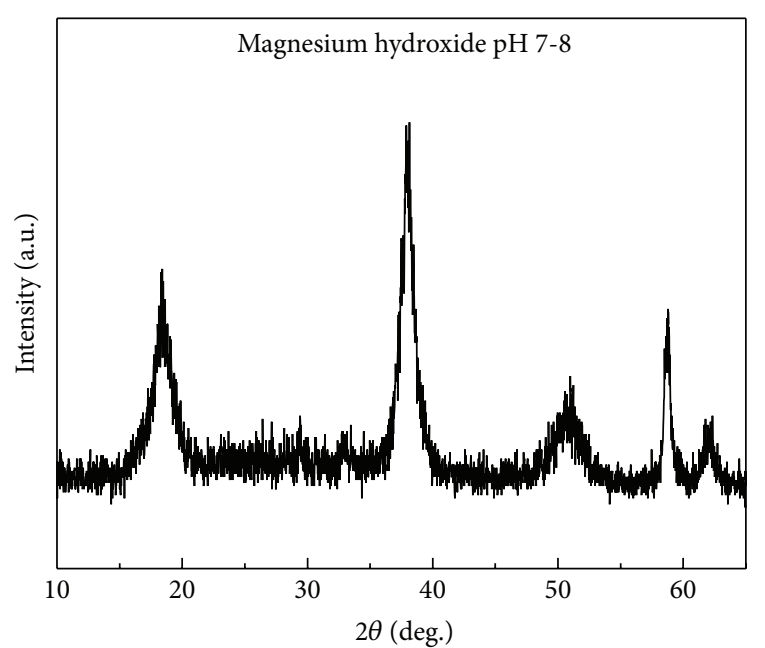

Figure 2: Powder X-ray diffraction pattern of magnesium hydroxide.

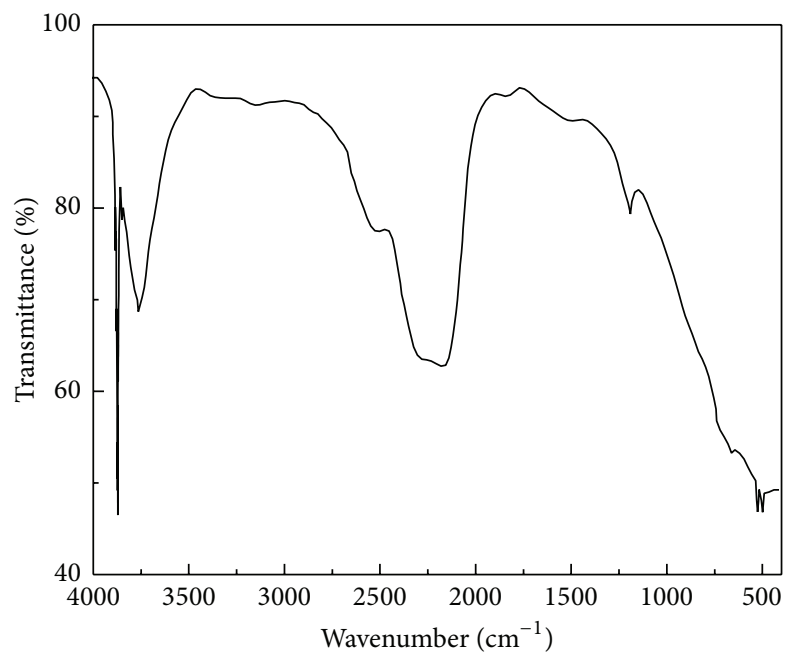

Figure 3: Infrared spectrum of magnesium hydroxide (precursor).

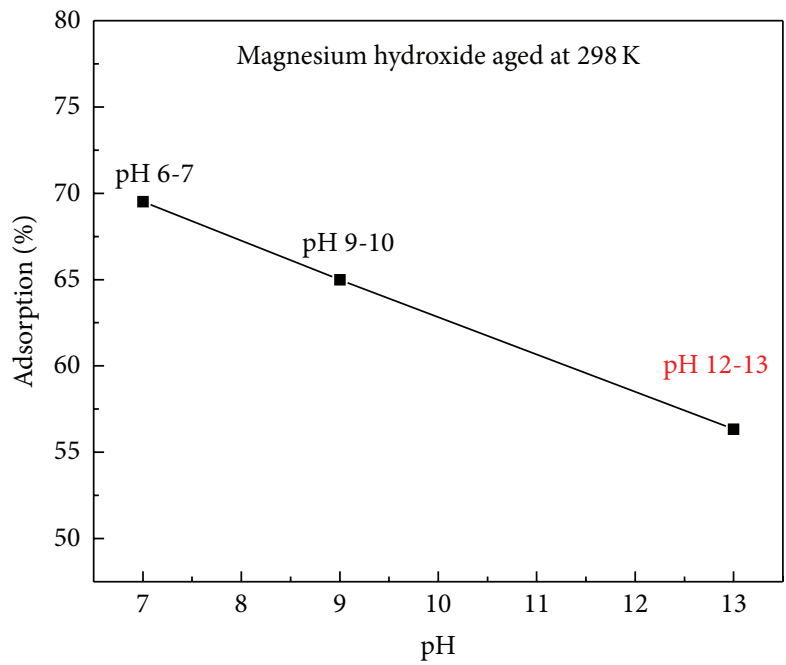

FIGURE 4: Effect of $\mathrm{pH}$ variation as a function of adsorption percentage.

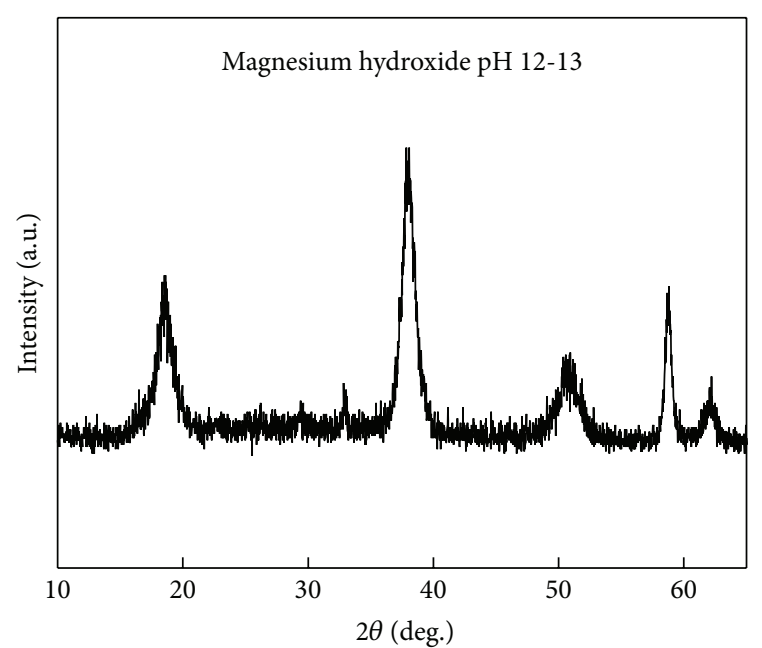

FIGURE 5: Powder X-ray diffraction pattern of magnesium hydroxide aged at $\mathrm{pH} 12-13$.

The effect of initial $\mathrm{pH}$ of the dye solution, dosage of adsorbent (magnesium hydroxide), dye concentration, temperature, and time were considered to validate the rate of dye removal.

3.1. Effect of $\mathrm{pH}$. The $\mathrm{pH}$ of dye solution on the percentage removal of indigo carmine was considered by varying the initial $\mathrm{pH}(6-7 ; 9-10$; and 13). The effect of $\mathrm{pH}$ (6-7, 9-10, and 13) on the adsorption of indigo carmine dye on magnesium hydroxide is shown in Figure 4. The percentage adsorption of indigo carmine on magnesium hydroxide was calculated using the following equation:

$$
q_{e}=\frac{\left(C_{0}-C_{e}\right)}{C_{0}} \times 100
$$

where $C_{0}$ and $C_{e}(\mathrm{mg} / 10 \mathrm{~mL})$ are the initial and equilibrium concentrations of indigo carmine dye in the solution.

At $\mathrm{pH}<6$, dissolution of magnesium hydroxide occurs. Hence we have chosen the $\mathrm{pH}>6$ for our investigation. It is found that maximum adsorption is close to neutral $\mathrm{pH}$ 6-7 and moderate adsorption at $\mathrm{pH}$ 9-10 and low adsorption at $\mathrm{pH} 12-13$ range. The decrease in the adsorption at higher $\mathrm{pH}$ might be due to the presence of negatively charged hydroxyl ions in the solution in addition to the surface hydroxyl groups of magnesium hydroxide.

Powder X-ray diffraction data and infrared spectroscopic data were recorded to monitor the structural changes that can be undergone on ageing magnesium hydroxide at $\mathrm{pH} 12-13$ (see Figures 5 and 6). It is clearly evident that there are no significant changes observed in the structure of magnesium hydroxide after performing adsorption experiments at $\mathrm{pH}$ $12-13$, which is based on the powder X-ray diffraction and infrared spectral data of magnesium hydroxide adsorbent (see Figures 5 and 6; Table 1 for band assignments). The infrared spectral data of magnesium hydroxide aged at $\mathrm{pH}$ 6-7 and 12-13 is given in Table 1. 


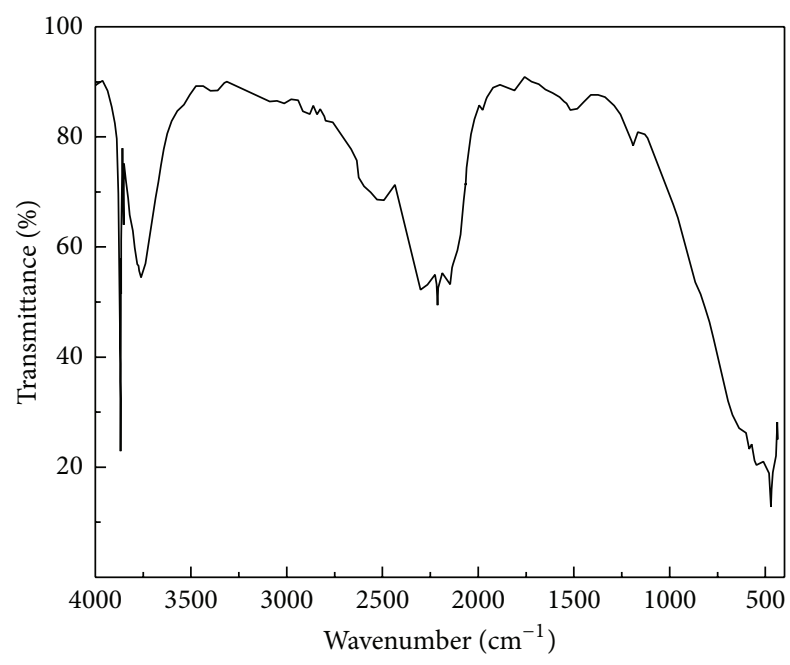

FIGURE 6: Infrared spectrum of magnesium hydroxide aged in $\mathrm{pH}$ 12-13 dye solution.

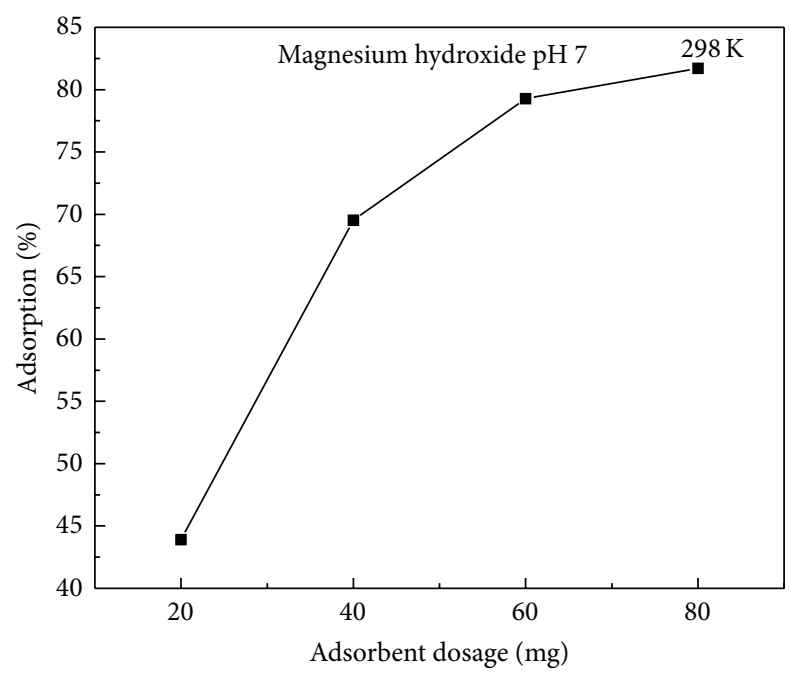

FIGURE 7: Variation of adsorbent dosage of magnesium hydroxide at pH 6-7.

3.2. Adsorbent Dose. Figure 7 shows the effect of adsorption of indigo carmine dye as a function of an increase in the dosage of magnesium hydroxide. The data clearly indicates that the adsorption increases with increase in the dose quantity. The equilibrium adsorption capacity was estimated and the adsorption of indigo carmine is maximum $(81.72 \%)$ when $80 \mathrm{mg}$ of magnesium hydroxide was used, while the adsorption capacity of indigo carmine dye was $69.52 \%$ when $40 \mathrm{mg}$ of magnesium hydroxide adsorbent was used. Generally at higher temperatures, adsorption will increase; hence we had used optimum quantity $(40 \mathrm{mg}$ ) of magnesium hydroxide adsorbent for all future investigations.

3.3. Dye Concentration. Dye concentrations, that is, 0.05$0.25 \mathrm{mg} / 10 \mathrm{~mL}$, were varied as a function of time at $\mathrm{pH} 6-$ 7 and 12-13 and the adsorption was monitored at $298 \mathrm{~K}$. The equilibrium adsorption $q_{e}$ was estimated. Figure 8 shows

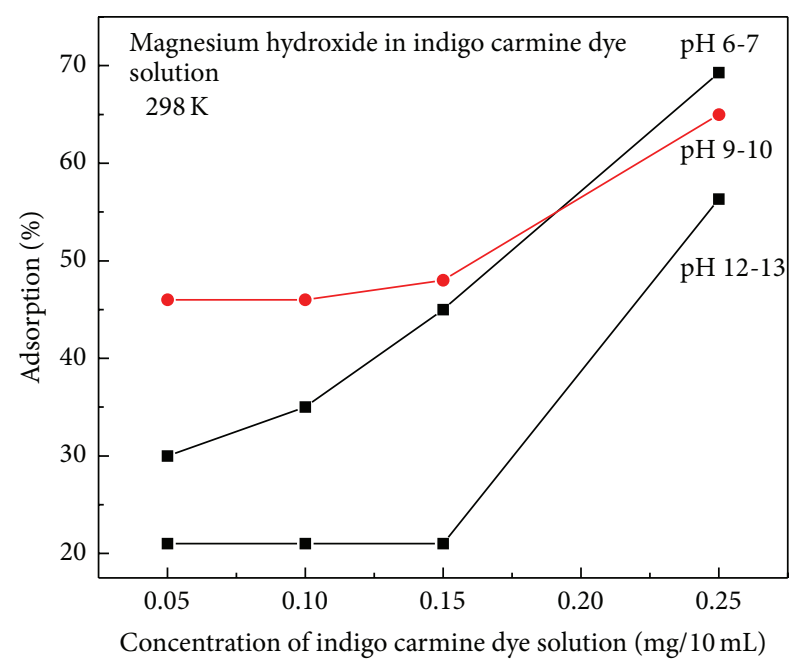

FIGURE 8: Effect of concentration as a function of percentage of adsorption.

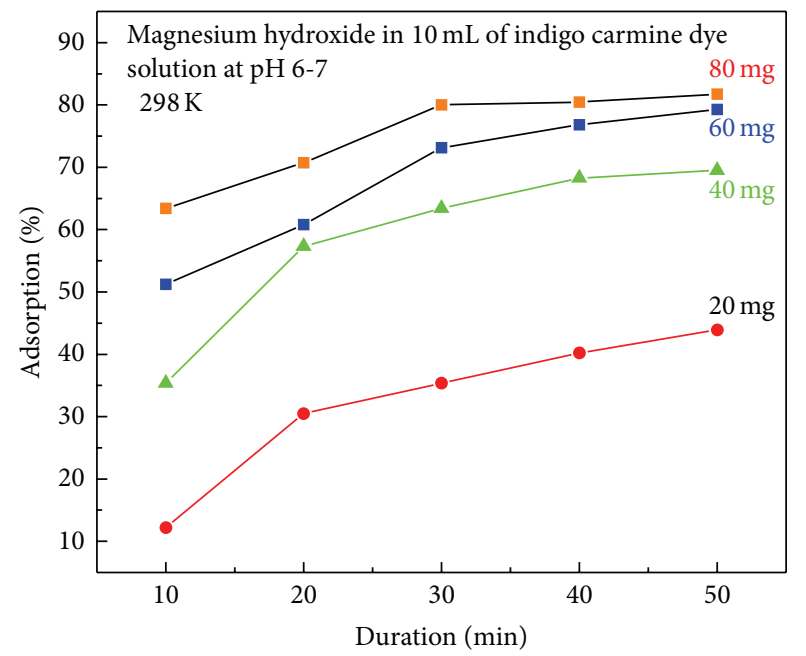

FIGURE 9: Effect of contact time on the adsorption of indigo carmine dye on magnesium hydroxide at $\mathrm{pH}$ 6-7.

the effect of concentration of adsorption of indigo carmine dye solution onto magnesium hydroxide.

3.4. Effect of Duration. Adsorption of indigo carmine on magnesium hydroxide at different contact times has been examined by adding $20 \mathrm{mg}, 40 \mathrm{mg}, 60 \mathrm{mg}$, and $80 \mathrm{mg}$ of adsorbent to indigo carmine dye solution $(0.25 \mathrm{mg} / 10 \mathrm{~mL})$. Figure 9 shows the effect of duration or contact time on the adsorption of indigo carmine on magnesium hydroxide at $\mathrm{pH}$ 6-7.

The adsorption maximum varied with variation in different doses and maximum of about $81 \%$ was observed when $80 \mathrm{mg}$ of magnesium hydroxide was used (duration 50 minutes).

3.5. Effect of Temperature. Temperature can affect the rate of adsorption drastically. Figure 10 shows the percentage of 
TABLE 1: Infrared spectral data of magnesium hydroxide precursor aged at different $\mathrm{pH}$ values.

\begin{tabular}{lcccc}
\hline Peak number & $\begin{array}{c}\text { Magnesium hydroxide } \\
\text { aged at pH 6-7 }\end{array}$ & Band assignment & $\begin{array}{c}\text { Magnesium hydroxide } \\
\text { aged at pH 13 }\end{array}$ & Band assignment \\
\hline & 3698 & Wave number $\left(\mathrm{cm}^{-1}\right)$ & & \\
1 & 3646 & $\mathrm{OH}$ stretch of $\mathrm{Mg}(\mathrm{OH})_{2}$ & 3697 & $\mathrm{OH}$ stretch of $\mathrm{Mg}(\mathrm{OH})_{2}$ \\
2 & 3444 & $\mathrm{OH}$ stretch of $\mathrm{Mg}(\mathrm{OH})_{2}$ & 3647 & $\mathrm{OH}$ stretch of $\mathrm{Mg}(\mathrm{OH})_{2}$ \\
3 & 1634 & $\mathrm{OH}$ stretch of $\mathrm{Mg}(\mathrm{OH})_{2}$ & 3445 & $\mathrm{OH}$ stretch of $\mathrm{Mg}(\mathrm{OH})_{2}$ \\
4 & $\mathrm{H}_{2} \mathrm{O}$ bend & 1645 & $\mathrm{H}_{2} \mathrm{O}$ bend \\
\hline
\end{tabular}
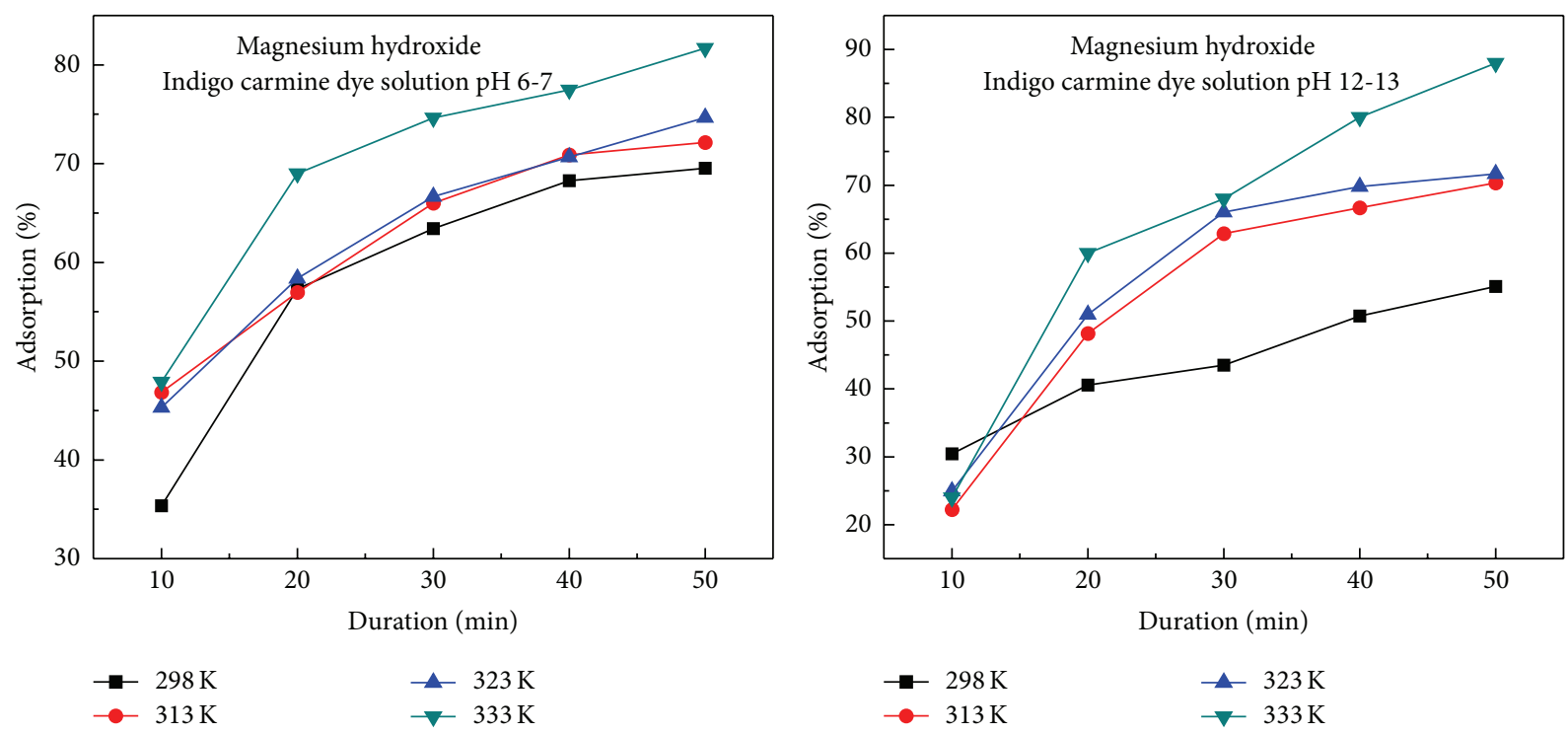

FIGURE 10: Effect of temperature on the adsorption of indigo carmine dye on magnesium hydroxide at different temperatures and pH values.

adsorption with increase in temperature (i.e., $298 \mathrm{~K}, 313 \mathrm{~K}$, $323 \mathrm{~K}$, and $333 \mathrm{~K})$. It is found that at $333 \mathrm{~K}$, the adsorption is maximum $(\mathrm{pH}=6-7,81.68 \%$, and $\mathrm{pH} 12-13,67.67 \%)$. With increase in temperature, adsorption also increases nonlinearly indicating that the process is endothermic in nature at lower temperatures. With increase in temperature, the free energy will be negative indicating the favourability of the process.

The Pearson correlation coefficient $\left(r / R^{2}\right)$ values are used to get an insight into the adsorption process of indigo carmine dye solution onto magnesium hydroxide. The value approaches unity at higher temperature indicating that the adsorption is more favourable at higher temperature.

3.6. Adsorption Isotherm Analyses. Different types of adsorption isotherm models were used to analyze the adsorption process of indigo carmine dye in aqueous solution onto magnesium hydroxide.

3.6.1. Freundlich Isotherm. Freundlich isotherm can be calculated using the following equation:

$$
\log q_{e}=\log k_{f}+\frac{1}{n} \log C_{e}
$$

where $q_{e}$ is the equilibrium adsorption capacity, $C_{e}$ is the equilibrium concentration $(\mathrm{mg} / 10 \mathrm{~mL}), k_{f}$ relates adsorption capacity of Freundlich constant, and $1 / n$ relates the intensity of Freundlich constant.

Freundlich isotherm model is applied in most cases for multilayer adsorption process and Figure 11 shows the graph of Freundlich isotherms of magnesium hydroxide at $\mathrm{pH}$ 6-7 and $\mathrm{pH} 12-13$, respectively. The graph is approaching linearity indicating the possibility of multilayer adsorption.

3.6.2. Temkin Isotherm. Temkin isotherm is evaluated using the following equation:

$$
\ln C_{e} \text { versus } \frac{q_{e}}{k_{T}}-\frac{b T}{k_{T}},
$$

where $T$ is the temperature (Kelvin), $b T$ is the heat of sorption, $k_{T}$ is the Temkin isotherm constant, and $q_{e}$ is the equilibrium adsorption capacity.

The data indicates that equilibrium adsorption capacity increases with increase in concentration and exhibits linearity for $\mathrm{pH}$ 6-7 and $\mathrm{pH}$ 12-13 (see Figure 12). Temkin isotherm may be applicable for the adsorption of indigo carmine onto magnesium hydroxide at $\mathrm{pH}$, that is, 6-7 and $\mathrm{pH} 12-13$. 

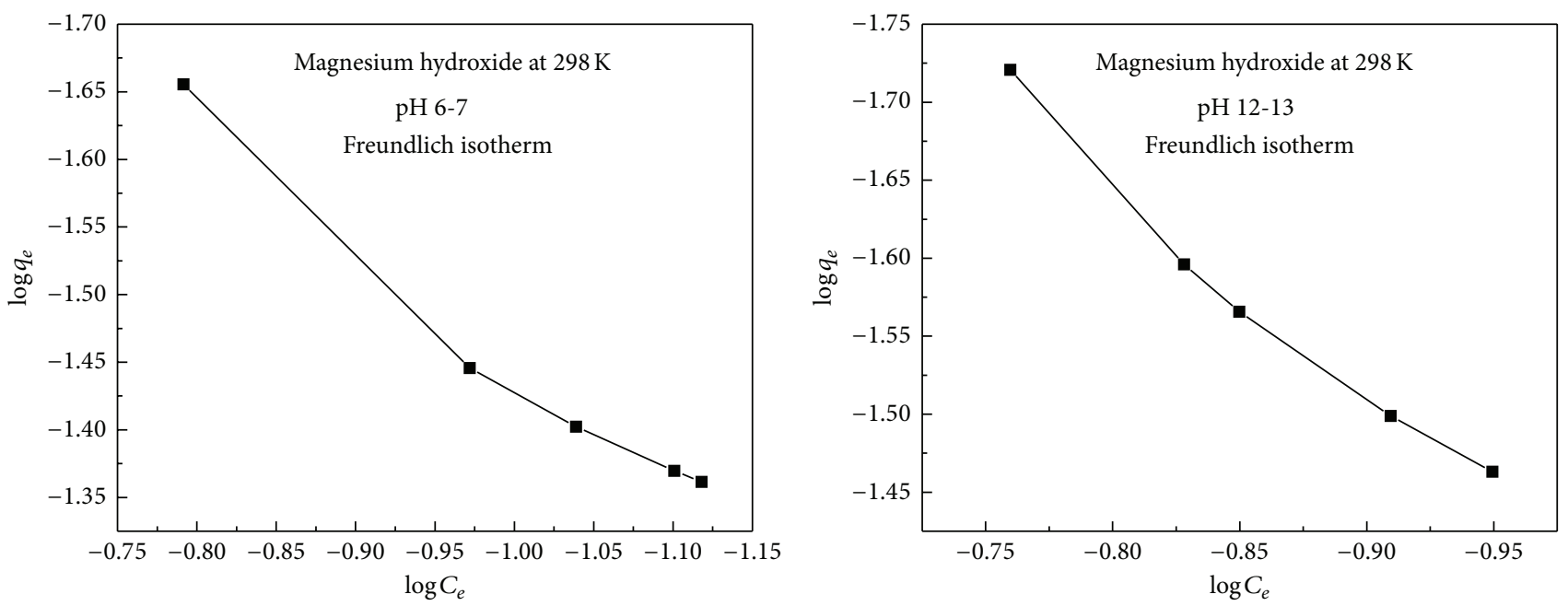

Figure 11: Plot of $-\log C_{e}$ versus $-\log q_{e}$ for Freundlich isotherms at $\mathrm{pH}$ 6-7 and $\mathrm{pH} 12-13$, respectively.

TABLe 2: (a) General data applicable to different isotherms (pH 6-7). (b) General data applicable to different isotherms (pH 12-13).

(a)

\begin{tabular}{lcccccccc}
\hline$C_{e}$ & $q_{e}$ & $\log C_{e}$ & $\log q_{e}$ & $\ln C_{e}$ & $\ln q_{e}$ & $1 / q_{e}$ & $C_{e} / q_{e}$ & $\log \left(C_{e} / q_{e}\right)$ \\
\hline 0.1616 & 0.0221 & -0.7915 & -1.6556 & -1.8226 & -3.8122 & 45.249 & 7.3122 & 0.86405 \\
0.1067 & 0.03583 & -0.9712 & -1.4458 & -2.2377 & -3.329 & 27.909 & 2.9779 & 0.4739 \\
0.09146 & 0.0396 & -1.0388 & -1.4023 & -2.3919 & -3.229 & 25.253 & 2.3096 & 0.36354 \\
0.0793 & 0.0427 & -1.10073 & -1.3696 & -2.535 & -3.1536 & 23.419 & 1.8571 & 0.26884 \\
0.0762 & 0.0435 & -1.11805 & -1.3615 & -2.5744 & -3.1349 & 22.99 & 1.7517 & 0.24346 \\
\hline
\end{tabular}

(b)

\begin{tabular}{lcccccccc}
\hline$C_{e}$ & $q_{e}$ & $\log C_{e}$ & $\log q_{e}$ & $\ln C_{e}$ & $\ln q_{e}$ & $1 / q_{e}$ & $C_{e} / q_{e}$ & $\log \left(C_{e} / q_{e}\right)$ \\
\hline 0.1739 & 0.0190 & -0.7597 & -1.7207 & -1.7493 & -3.9633 & 52.5624 & 9.1406 & 0.96097 \\
0.1486 & 0.0254 & -0.8281 & -1.5960 & -1.9065 & -3.6730 & 39.4477 & 5.8619 & 0.76804 \\
0.1413 & 0.0272 & -0.8498 & -1.5658 & -1.9569 & -3.6045 & 36.7985 & 5.1996 & 0.715969 \\
0.1232 & 0.0317 & -0.9094 & -1.4989 & -2.0939 & -3.4514 & 31.5457 & 3.8864 & 0.58955 \\
0.1123 & 0.0344 & -0.9495 & -1.4631 & -2.1866 & -3.3697 & 29.0487 & 3.2622 & 0.51351 \\
\hline
\end{tabular}

The correlation coefficients for the different isotherm models and the equations used to calculate the $R / r$ values.

3.6.3. Redlich-Peterson Isotherm. Consider the following:

$$
\log C_{e}=\frac{1}{\log \left(b_{R} \beta\right)}\left(K_{R}+\log \frac{C_{e}}{q_{e}}\right),
$$

where $K_{r}, b_{R}$, and $\beta$ are Redlich-Peterson constants which are used to calculate the Redlich-Peterson isotherm.

Figure 13 shows the plot of $\ln C_{e}$ versus $-\log \left(C_{e} / q_{e}\right)$, which is a straight line with a slope $\left(K_{R}+\log \left(C_{e} / q_{e}\right)\right)$.

The importance of Redlich-Peterson isotherm is that it is a combination of Langmuir and Freundlich isotherms. The data fits reasonably well at $\mathrm{pH}$ 6-7 and $\mathrm{pH} 12-13$ indicating it to be of Redlich-Peterson isotherm model.

Table 2 shows the parameters and their values used for deriving information about various types of isotherms.

Adsorption isotherm better fits in the following increasing order based on the correlation coefficient $\left(R^{2}\right)$ values when indigo carmine dye solution was maintained at $\mathrm{pH} 6$ 7 (magnesium hydroxide-adsorbent): Harkin-Jura isotherm
(1.0041) < Langmuir isotherm (1.0068). While $R^{2}$ value of Langmuir isotherm and Harkin-Jura isotherm values are 1 indicating that adsorption process occurs first as a monolayer followed by multilayer process at $\mathrm{pH}$ 6-7 when magnesium hydroxide was used as adsorbent and indigo carmine dye solution.

Adsorption isotherm better fits in the following increasing order based on the correlation coefficient $\left(R^{2}\right)$ values when indigo carmine dye solution was maintained at $\mathrm{pH} 12$ 13 (magnesium hydroxide-adsorbent): Langmuir (0.9796) < Temkin isotherm (1.016). While $R^{2}$ value of Langmuir isotherm and Temkin isotherms are 1 indicating that adsorption process occurs at $\mathrm{pH}$ 12-13 when magnesium hydroxideadsorbent was used as adsorbent and indigo carmine dye solution.

3.7. Kinetics of Adsorption Process. Kinetic models (pseudofirst order and pseudo-second order rate equations) were 

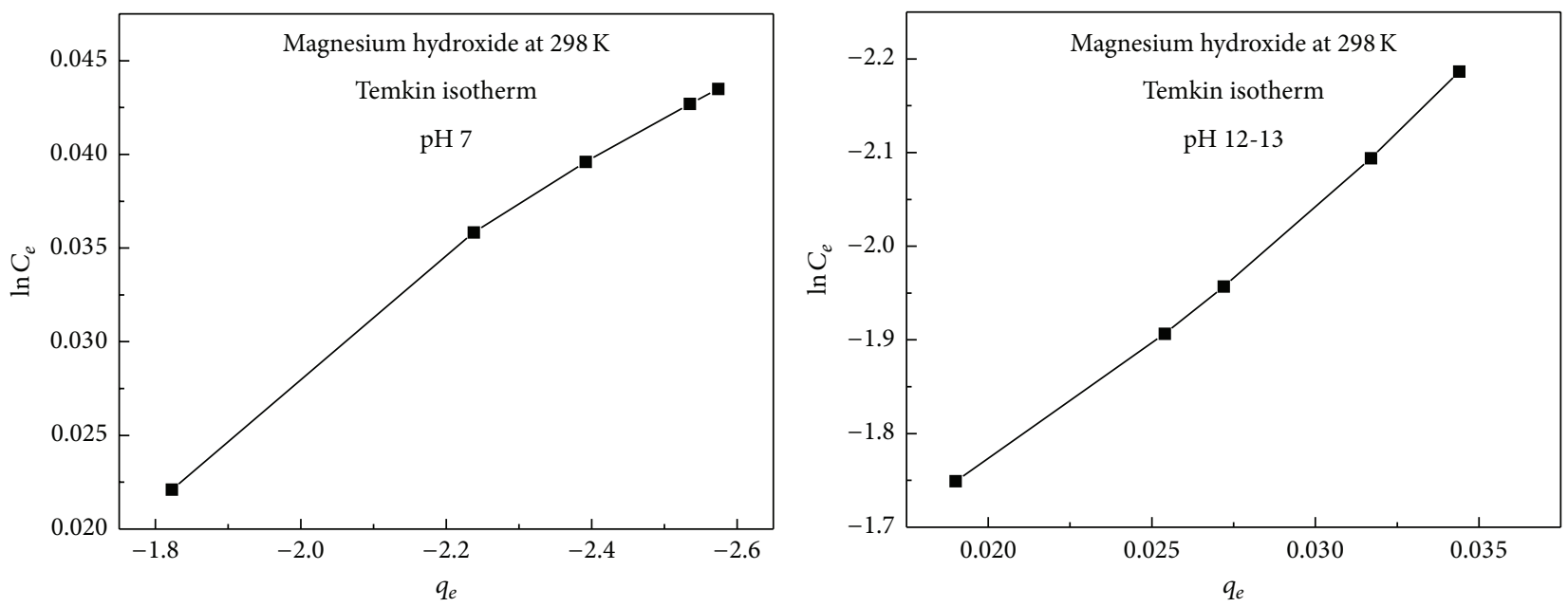

FIgURE 12: Plot of $\ln C_{e}$ versus $q_{e}$ for Temkin isotherms at $\mathrm{pH}$ 6-7 and $\mathrm{pH} 12-13$, respectively.
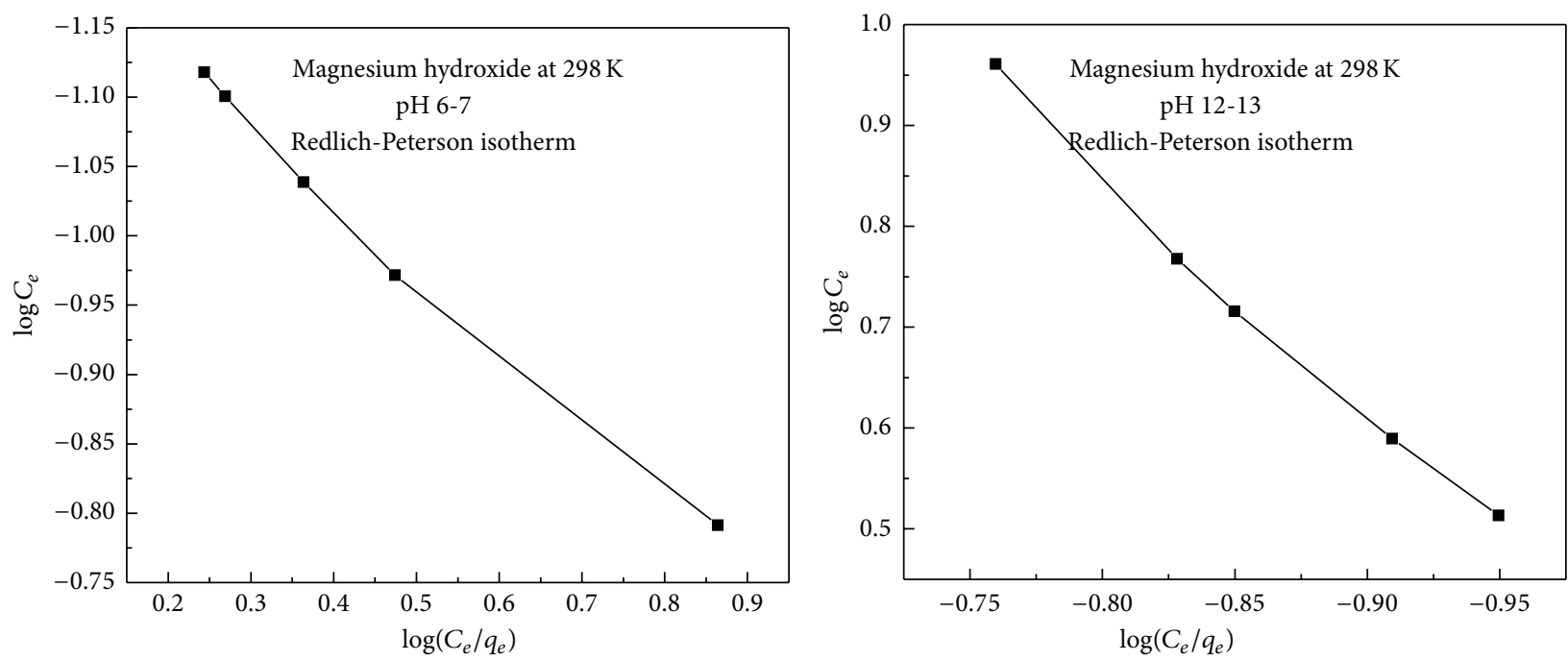

Figure 13: Plot of $\log C_{e}$ versus $-\log \left(C_{e} / q_{e}\right)$ for Redlich-Peterson isotherms at $\mathrm{pH}$ 6-7 and $\mathrm{pH} 12-13$, respectively.
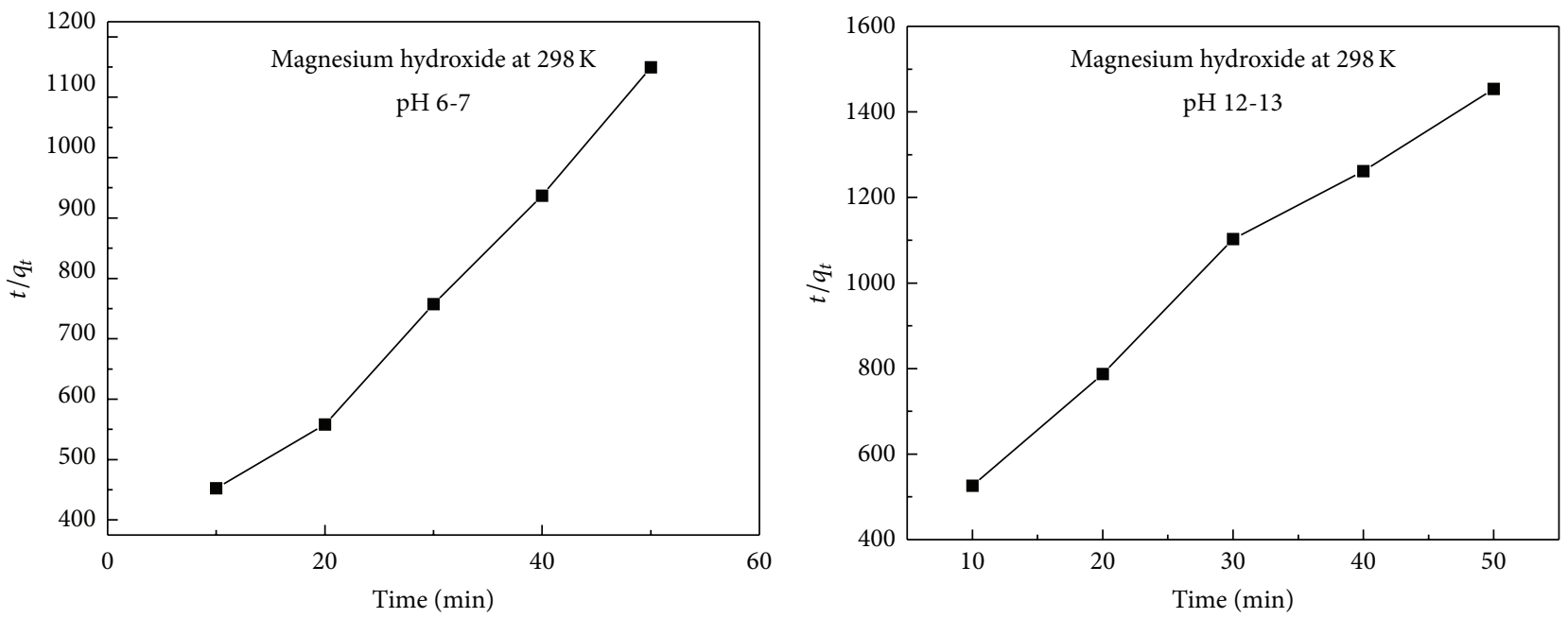

FIGURE 14: Pseudo-second order kinetics. 
TABLE 3: (a) List of parameters used to evaluate the pseudo-second order rate equation (pH 6-7). (b) List of parameters used to evaluate the pseudo-second order rate equation ( $\mathrm{pH} 12-13)$.

(a)

\begin{tabular}{lccccc}
\hline \multirow{2}{*}{ Kinetic model } & \multicolumn{4}{c}{ Parameters } \\
& Dye $(\mathrm{mg} / 100 \mathrm{~mL}) C_{0}$ & $q_{e}$ (experimental) & $K^{2}$ & $q_{e}$ (calculated) & $R^{2}$ \\
\hline Pseudo-second order kinetics & 0.25 & 0.0435 & 52.48803 & 0.05217 & 0.09945 \\
\hline
\end{tabular}

(b)

\begin{tabular}{lccccc}
\hline \multirow{2}{*}{ Kinetic model } & \multicolumn{4}{c}{ Parameters } \\
& Dye $(\mathrm{mg} / 100 \mathrm{~mL}) C_{0}$ & $q_{e}$ (experimental) & $K^{2}$ & $q_{e}$ (calculated) & $R^{2}$ \\
\hline Pseudo-second order kinetics & 0.25 & 0.0344 & 229.6875 & 0.03809 & 0.992186 \\
\hline
\end{tabular}

TABLE 4: (a) List of parameters used to evaluate the pseudo-second order rate equation (pH 6-7). (b) List of parameters used to evaluate the pseudo-second order rate equation ( $\mathrm{pH} 12-13)$.

(a)

\begin{tabular}{|c|c|c|c|c|}
\hline Time (min) & $t / q_{t}$ & $t^{2}$ & $t / q_{t}^{2}$ & $t \times t / q_{t}$ \\
\hline 10 & 452.489 & 100 & 204746.29 & 4524.89 \\
\hline 20 & 558.1915 & 400 & 311577.750 & 11163.83 \\
\hline 30 & 757.5757 & 900 & 573920.94 & 22727.271 \\
\hline 40 & 936.768 & 1600 & 877534.2858 & 37470.72 \\
\hline 50 & 1149.453 & 2500 & 1321242.19 & 57472.65 \\
\hline$\sum t=150$ & $\sum \frac{t}{q_{t}}=3854.4772$ & $\sum t^{2}=5500$ & $\sum \frac{t}{q_{t}^{2}}=3289021.472$ & $\sum\left(t \times \frac{t}{q_{t}}\right)=133359.36$ \\
\hline
\end{tabular}

(b)

\begin{tabular}{|c|c|c|c|c|}
\hline Time (min) & $t / q_{t}$ & $t^{2}$ & $t / q_{t}^{2}$ & $t \times t / q_{t}$ \\
\hline 10 & 526.3158 & 100 & 277008.3213 & 5263.158 \\
\hline 20 & 787.4015 & 400 & 620001.1222 & 15748.03 \\
\hline 30 & 1102.9412 & 900 & 1216479.291 & 33088.236 \\
\hline 40 & 1261.8297 & 1600 & 1592214.192 & 50473.188 \\
\hline 50 & 1453.4884 & 2500 & 2112628.529 & 72674.42 \\
\hline$\sum t=150$ & $\sum \frac{t}{q_{t}}=5131.9766$ & $\sum t^{2}=5500$ & $\sum \frac{t}{q_{t}^{2}}=5818331.456$ & $\sum\left(t \times \frac{t}{q_{t}}\right)=177247.032$ \\
\hline
\end{tabular}

evaluated to get an insight into the adsorption process of indigo carmine dye onto magnesium hydroxide [20,36]. The data does not fit linearly for pseudo-first order rate kinetics.

3.7.1. Pseudo-Second Order Rate Equation. The adsorption process was examined to fit for pseudo-second order rate equation. If the interaction between the indigo carmine dye and magnesium oxide is through charge transfer then the reaction should be pseudo-second order. The parameters used to determine pseudo-second order rate equation during the adsorption of indigo carmine dye onto magnesium hydroxide are given in Tables 3 and 4 (see Figure 14). The $r$ or $R^{2}$ value (calculated) 0.9945 indicates that it is a reasonably good fit and the experimental $(0.0435)$ and calculated $q_{e}$ values $(0.05)$ are closer indicating that the adsorption might be of pseudo-second order in nature at $\mathrm{pH}$ 6-7. At $\mathrm{pH}$ 1213 , the calculated $r$ or $R^{2}$ value is 0.9921 which indicates that it is a reasonably good fit. But the differences between the experimental $(0.0344)$ and calculated $q_{e}$ values $(0.038)$ are large indicating that the adsorption follows pseudo-second order at $\mathrm{pH} 12-13$.

3.8. Thermodynamic Parameters. The difference in the free energy $\left(\Delta G^{\circ}\right)$ with change in the temperature during the adsorption process of indigo carmine onto magnesium hydroxide at $\mathrm{pH} 7$ and $\mathrm{pH} 13$ is given in Table 5 . The negative free energy values at higher temperature indicate that the adsorption process is endothermic at pHs (6-7/12-13).

\section{Conclusions}

Different types of adsorption isotherms of indigo carmine dye on magnesium hydroxide were evaluated to understand the nature of interaction between the adsorbent and adsorbate. Langmuir and Harkin-Jura isotherms fit well at $\mathrm{pH} 7$ indicating that monolayer and multilayer adsorption occurs simultaneously. Langmuir and Temkin isotherm models are effective at $\mathrm{pH} 12-13$ indicating that adsorption is a monolayer process. The percentage of adsorption of indigo carmine dye 
TABLE 5: (a) Thermodynamic parameters for adsorption of indigo carmine onto magnesium hydroxide at $\mathrm{pH}$ 7. (b) Thermodynamic parameters for adsorption of indigo carmine onto magnesium hydroxide at $\mathrm{pH} 13$.

(a)

\begin{tabular}{lcc}
\hline Adsorbent & Temperature $(\mathrm{K})$ & $\Delta G^{\circ}\left(\mathrm{kJ} \mathrm{mol}^{-1}\right)$ \\
\hline & 298 & 4.5497 \\
Magnesium hydroxide & 313 & 8.0641 \\
& 323 & -0.1369 \\
& 333 & -0.4484 \\
\hline
\end{tabular}

(b)

\begin{tabular}{lcc}
\hline Adsorbent & Temperature $(\mathrm{K})$ & $\Delta G^{\circ}\left(\mathrm{kJ} \mathrm{mol}^{-1}\right)$ \\
\hline \multirow{3}{*}{ Magnesium hydroxide } & 298 & 3.4227 \\
& 313 & 1.3041 \\
& 323 & 1.0203 \\
& 333 & -2.2029 \\
\hline
\end{tabular}

from aqueous solution onto magnesium hydroxide maintained at $\mathrm{pH} 6-7$ and at $333 \mathrm{~K}$ is $20 \%$ higher than that at $\mathrm{pH}$ 12-13. The results demonstrate that the process of adsorption is endothermic and spontaneous. Therefore, magnesium hydroxide is used as a low cost adsorbent for the removal of indigo carmine dye solution.

\section{Conflict of Interests}

The authors declare that there is no conflict of interests regarding the publication of this paper.

\section{References}

[1] H. Klaus, Industrial Dyes-Chemistry, Properties, Applications, Wiley-VCH, Weinheim, Germany, 2003.

[2] A. Dabrowski, "Adsorption-from theory to practice," Advances in Colloid and Interface Science, vol. 93, no. 1-3, pp. 135-244, 2001.

[3] A. Reife, "Dyes, environmental chemistry," in Kirk-Othmer Encyclopedia of Chemical Technology, John Wiley \& Sons, 2000.

[4] A. Olness, "Water quality: prevention, identification and management of diffuse pollution," Journal of Environment Quality, vol. 24, no. 2, p. 383, 1995.

[5] H. Zollinger, Color Chemistry: Synthesis, Properties and Applications of Organic Dyes and Pigments, VCH Publisher, New York, NY, USA, 2nd edition, 1991.

[6] Z. Song, L. Chen, J. Hu, and R. Richards, "NiO(111) nanosheets as efficient and recyclable adsorbents for dye pollutant removal from wastewater," Nanotechnology, vol. 20, no. 27, Article ID 275707, pp. 1-20, 2009.

[7] A. K. Golder, A. N. Samanta, and S. Ray, "Anionic reactive dye removal from aqueous solution using a new adsorbent-sludge generated in removal of heavy metal by electrocoagulation," Chemical Engineering Journal, vol. 122, no. 1-2, pp. 107-115, 2006.

[8] S. M. Ghoreishi and R. Haghighi, "Chemical catalytic reaction and biological oxidation for treatment of non-biodegradable textile effluent," Chemical Engineering Journal, vol. 95, no. 1-3, pp. 163-169, 2003.
[9] G. Crini, "Non-conventional low-cost adsorbents for dye removal: a review," Bioresource Technology, vol. 97, no. 9, pp. 1061-1085, 2006.

[10] O. Sacco, M. Stoller, V. Vaiano, P. Ciambelli, A. Chianese, and D. Sannino, "Photocatalytic degradation of organic dyes under visible light on n-doped $\mathrm{TiO}_{2}$ photocatalysts," International Journal of Photoenergy, vol. 2012, Article ID 626759, 8 pages, 2012.

[11] H. S. Rai, M. S. Bhattacharyya, J. Singh, T. K. Bansal, P. Vats, and U. C. Banerjee, "Removal of dyes from the effluent of textile and dyestuff manufacturing industry: a review of emerging techniques with reference to biological treatment," Critical Reviews in Environmental Science and Technology, vol. 35, no. 3, pp. 219-238, 2005.

[12] K. K. H. Choy, G. McKay, and J. F. Porter, "Sorption of acid dyes from effluents using activated carbon," Resources, Conservation and Recycling, vol. 27, no. 1-2, pp. 57-71, 1999.

[13] S. Babel and T. A. Kurniawan, "Low-cost adsorbents for heavy metals uptake from contaminated water: a review," Journal of Hazardous Materials, vol. 97, no. 1-3, pp. 219-243, 2003.

[14] A. K. Jain, V. K. Gupta, A. Bhatnagar, and Suhas, "Utilization of industrial waste products as adsorbents for the removal of dyes," Journal of Hazardous Materials, vol. 101, no. 1, pp. 31-42, 2003.

[15] F. Derbyshire, M. Jagtoyen, R. Andrews, A. Rao, I. MartinGullon, and E. Grulke, "Carbon materials in environmental applications," in Chemistry and Physics of Carbon, L. R. Radovic, Ed., vol. 27, pp. 1-66, Marcel Dekker, New York, NY, USA, 2001.

[16] V. K. Gupta, R. Kumar, A. Nayak, T. A. Saleh, and M. A. Barakat, "Adsorptive removal of dyes from aqueous solution onto carbon nanotubes: a review," Advances in Colloid and Interface Science, vol. 193-194, pp. 24-34, 2013.

[17] S. Song, Y. Ma, H. Shen, M. Zhang, and Z. Zhang, "Removal and recycling of ppm levels of methylene blue from an aqueous solution with graphene oxide," RSC Advances, vol. 5, no. 35, pp. 27922-27932, 2015.

[18] Z. Yan, W. Yao, L. Hu, D. Liu, C. Wang, and C. Lee, "Progress in the preparation and application of three-dimensional graphenebased porous nanocomposites," Nanoscale, vol. 7, no. 13, pp. 5563-5577, 2015.

[19] Y. Yang, Y. Xie, L. Pang et al., "Preparation of reduced graphene oxide/poly(acrylamide) nanocomposite and its adsorption of $\mathrm{Pb}$ (II) and methylene blue," Langmuir, vol. 29, no. 34, pp. 1072710736, 2013.

[20] H. Li, J. Fan, Z. Shi, M. Lian, M. Tian, and J. Yin, "Preparation and characterization of sulfonated graphene-enhanced poly (vinyl alcohol) composite hydrogel and its application as dye absorbent," Polymer, vol. 60, pp. 96-106, 2015.

[21] X. Huang, X. Qi, F. Boey, and H. Zhang, "Graphene-based composites," Chemical Society Reviews, vol. 41, no. 2, pp. 666686, 2012.

[22] M. F. R. Pereira, S. F. Soares, J. J. M. Órfão, and J. L. Figueiredo, "Adsorption of dyes on activated carbons: influence of surface chemical groups," Carbon, vol. 41, no. 4, pp. 811-821, 2003.

[23] S. Chatterjee, M. W. Lee, and S. H. Wooa, "Adsorption of congo red by chitosan hydrogel beads impregnated with carbon nanotubes," Bioresource Technology, vol. 101, no. 6, pp. 18001806, 2010.

[24] J. W. Owens, "Chemical toxicity indicators for human health: case study for classification of chronic noncancer chemical hazards in life-cycle assessment," Environmental Toxicology and Chemistry, vol. 21, no. 1, pp. 207-225, 2002. 
[25] X. N. Zhang, G. Y. Mao, Y. B. Jiao, Y. Shang, and R. P. Han, "Adsorption of anionic dye on magnesium hydroxidecoated pyrolytic bio-char and reuse by microwave irradiation," International Journal of Environmental Science and Technology, vol. 11, no. 5, pp. 1439-1448, 2014.

[26] J. X. Lin and L. Wang, "Adsorption of dyes using magnesium hydroxide-modified diatomite," Desalination and Water Treatment, vol. 8, no. 1-3, pp. 263-271, 2009.

[27] Y. Liu and J. H. Zhao, "Removal of reactive dyes from wastewater by magnesium hydroxide coagulation assisted with ultrasonic," Advanced Materials Research, vol. 790, pp. 77-80, 2013.

[28] T. N. Ramesh, D. V. Kirana, T. N. Mohana Kumari, and A. Ashwini, "Adsorption studies of indigo carmine dye by magnesium oxide," International Journal of Science Research, vol. 1, no. 4, pp. 495-501, 2012.

[29] T. Hara, M. Ishikawa, J. Sawada, N. Ichikuni, and S. Shimazu, "Creation of highly stable monomeric Pd(II) species in an anion-exchangeable hydroxy double salt interlayer: application to aerobic alcohol oxidation under an air atmosphere," Green Chemistry, vol. 11, no. 12, pp. 2034-2040, 2009.

[30] T. N. Ramesh, T. N. Mohana Kumari, D. V. Kirana, A. Ashwini, and J. M. Prathiba, "Kinetics, thermodynamics and adsorption isotherm of alizarin red dye using calcium oxide," in Proceedings of the National Conference on "Challenges and Opportunities for Chemical Sciences in 21st Century”, pp. 100-108, Bangalore, India, 2013.

[31] T. N. Ramesh, A. Ashwini, T. N. Mohana Kumari, D. V. Kirana, and Theertha, "Adsorption studies of indigo carmine using calcium oxide," in Proceedings of the National Conference on "Challenges and Opportunities for Chemical Sciences in 21st Century”, pp. 75-83, Karnataka, India, January 2013.

[32] T. N. Ramesh, J. M. Prathiba, D. V. Kirana, T. N. Mohana Kumari, and A. Ashwini, "Adsorption dynamics and equilibrium uptake for the removal of alizarin red dye using magnesium oxide," in Proceedings of the National Conference on "Challenges and Opportunities for Chemical Sciences in 21st Century”, pp. 113-121, Bangalore, India, 2013.

[33] K. Nakamoto, Infrared and Raman Spectra of Inorganic and Coordination Compounds, Part B, Applications in Coordination, Organometallic, and Bioinorganic Chemistry, John Wiley \& Sons, New York, NY, USA, 6th edition, 2008.

[34] W. White, "Infrared characterization of water and hydroxyl ion in the basic nickel carbonate minerals," The American Mineralogist, vol. 56, no. 1-2, pp. 46-53, 1971.

[35] R. A. Nyquist and R. O. Kagel, Handbook of Infrared and Raman Spectra of Inorganic Compounds and Organic Salts, Infrared Spectra of Inorganic Compounds, Academic Press, New York, NY, USA, 1st edition, 1971.

[36] K. Porkodi and K. V. Kumar, "Equilibrium, kinetics and mechanism modeling and simulation of basic and acid dyes sorption onto jute fiber carbon: eosin yellow, malachite green and crystal violet single component systems," Journal of Hazardous Materials, vol. 143, no. 1-2, pp. 311-327, 2007. 

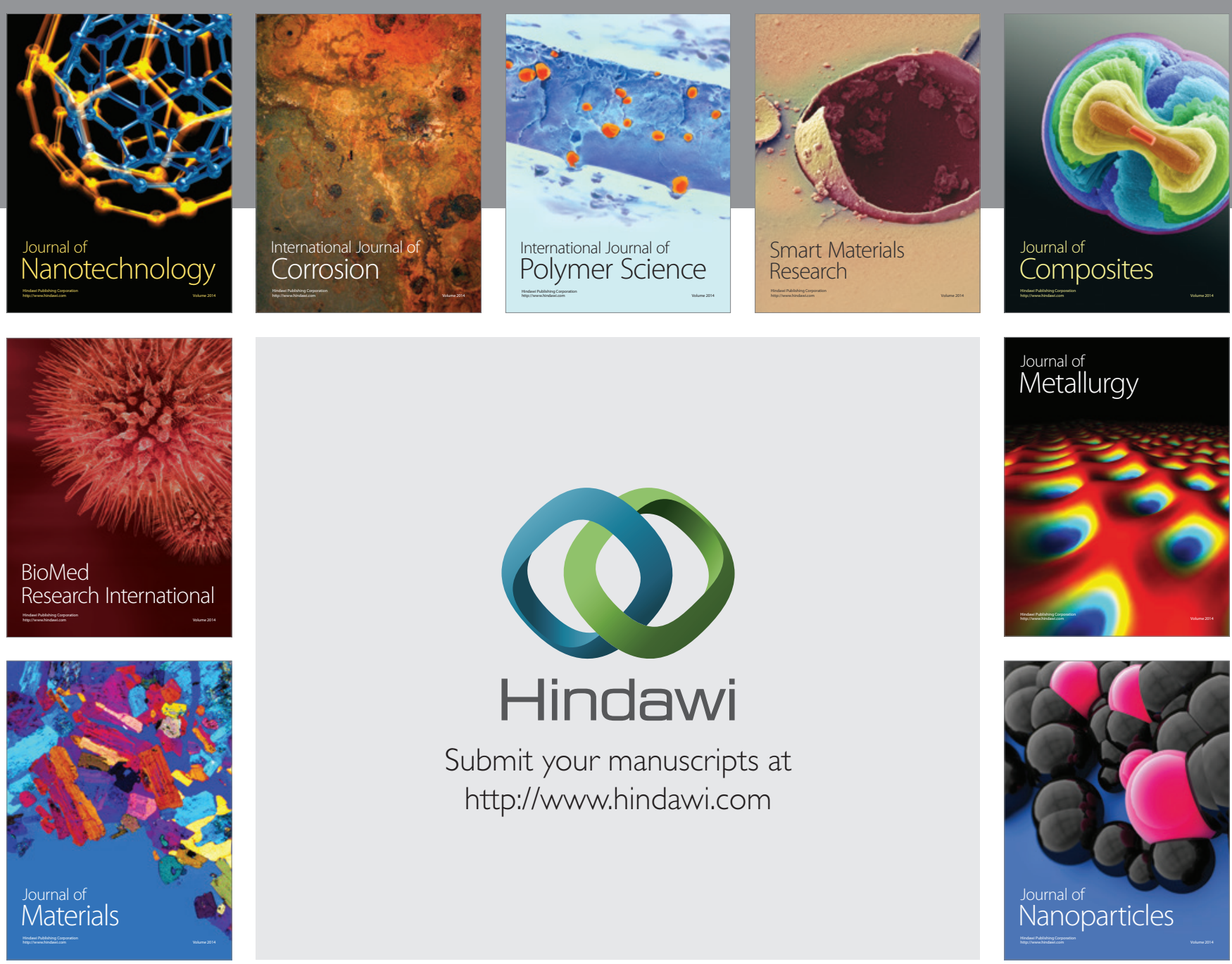

Submit your manuscripts at http://www.hindawi.com
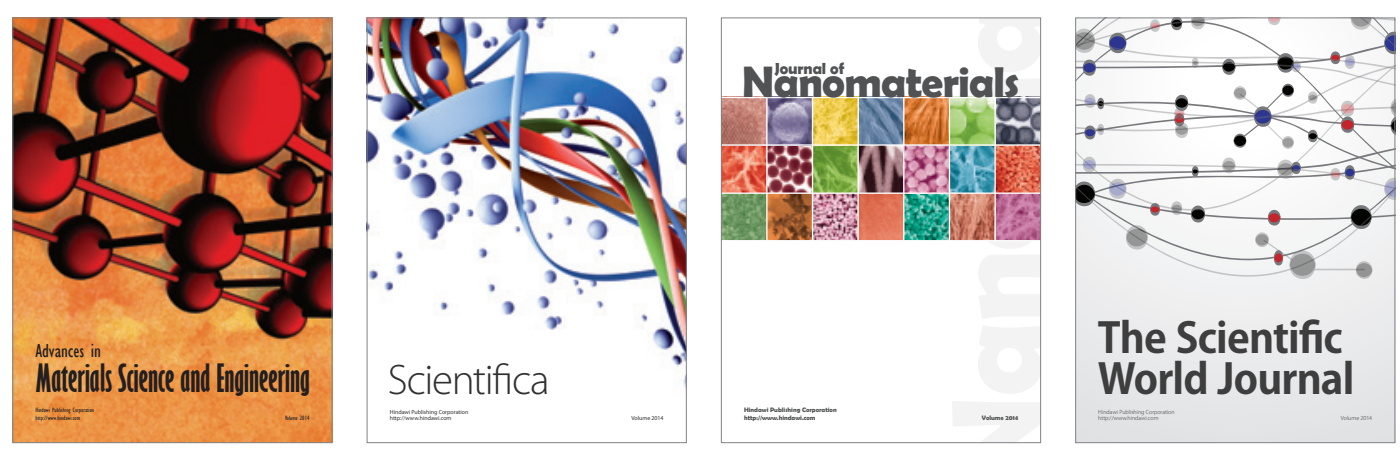

\section{The Scientific World Journal}
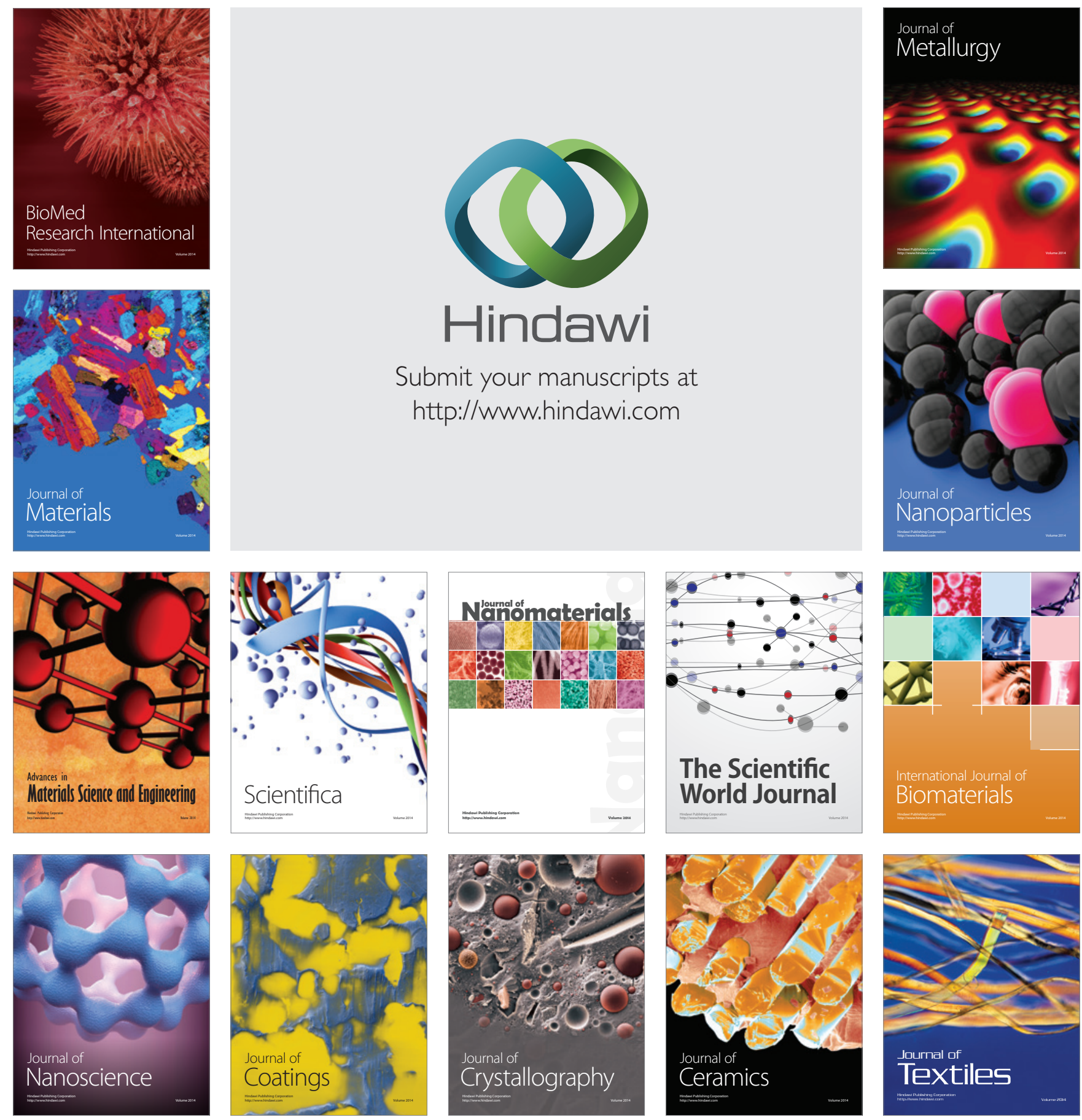